\title{
Comparison of the Belgian interventions levels and the new ICRP recommendations for emergency exposures
}

\author{
D. BRAEKERS, C. TURCANU, G. OLYSLAEGERS, J. CAMPS
}

\begin{abstract}
The new recommendations on emergency exposure situations of the International Commission on Radiological Protection (ICRP) advise a reference level for the residual dose in a range of between 20 and $100 \mathrm{mSv}$ effective dose (acute or per year). At the same time, the protection strategy should account for the simultaneous consideration of all the exposure pathways, as well as all of the protective actions. Similarly to other countries, the actual Belgian nuclear emergency plan is based on individual projected doses (thyroid committed dose and total effective doses) and independent protective actions that mainly focus on the early phase of an emergency situation. The two approaches are compared in this study on the basis of the projected and residual dose calculations obtained using JRODOS and the Belgian Noodplan models for different radiological or nuclear accidental scenarios. The comparison has been made by considering separately the early and the late phase contributions. The ingestion dose has been investigated from the predicted deposition values and compared to the single level of the ICRP 109 recommendations.
\end{abstract}

Keywords: Nuclear and radiological emergency/Belgian intervention levels /

ICRP 109 recommendations

\section{Introduction}

The 2007 recommendations of the International Commission on Radiological Protection (ICRP, 2009) on the public exposure to ionising radiation during a nuclear or radiological emergency situation advise the national authorities to use an effective residual dose between 20 and $100 \mathrm{mSv}$ (acute or per year) as a single reference level. In addition to this threshold, the commission recommends, among others, to simultaneously consider all the potential exposure pathways and all relevant

SCK $\cdot$ CEN, Belgian Nuclear Research Centre, Institute for Environment, Health and Safety, Boeretang 200, B-2400 Mol, Belgium. 
protection options for a better optimization of the radiological protection strategy. By consequence reference levels below $20 \mathrm{mSv}$ can be preferred in the case of a response to an event involving projected exposure below $20 \mathrm{mSv}$.

If we compare this new approach to the actual strategy and intervention levels used by different states for the implementation of countermeasures in case of nuclear or radiological emergencies (NEA, 2003) we can observe some differences:

1. In general, several intervention levels are used for the different available protective actions (e.g. sheltering, evacuation, temporary or permanent relocation, stable iodine prophylaxis, foodstuff restriction...). Effective doses (averted or projected) integrated over a short and a medium period of time, e.g. 24 hours and 7 days, are often considered as good thresholds for the sheltering and evacuation actions, respectively. The committed thyroid dose is usually the basis for the intervention level used for stable iodine prophylaxis in case of an accidental release of radioactive iodine.

2. By using only one effective residual dose as a reference level for all the protective actions during a nuclear or radiological emergency situation, the new ICRP 109 recommendations do not make any real distinctions anymore between contributions to the total dose during the early phase or the late phase of an emergency situation. Moreover, with an integration time of 1 year for the residual dose, the long term consequences from chronic exposure to the external irradiation from a contaminated area or from the contaminated food ingestion become predominant as compared to the other pathways.

3. The ingestion pathway is often treated separately for the dose assessment during the early phase of a nuclear/radiological emergency situation, while the Commission recommends considering all the exposures pathways at the same time.

The Belgian nuclear emergency plan is a good example for the actual situation as regards the management of a nuclear/radiological crisis situation (Royal Decree, 2003). The implementation of countermeasures is based on a set of different intervention levels, corresponding to individual protective actions for the population (Tab. I). In general, these protective actions have to be considered independently from each other. The ingestion pathway is treated separately from the other contributions (cloudshine, inhalation and groundshine) for the dose calculation. In our current approach we assume that during an emergency situation, food restrictions as a protective action are automatically advised once a certain level of radioactivity deposited on the soil is exceeded (i.e. iodine or caesium); it is also assumed that this protective action keeps the food chain contribution to the total effective dose below $5 \mathrm{mSv} / \mathrm{y}$ (Govaerts, 1992). These deposition levels, expressed in Bq/ $\mathrm{m}^{2}$, are derived from the maximal levels of contamination in foodstuffs which guarantee their free circulation in the European Union market (Euratom, 1987) and are shown in Table II. 
Table I

Interventions levels of the Belgian nuclear emergency plan during the early phase (Royal Decree, 2003).

\begin{tabular}{lcl}
\hline Protective action & Intervention level $(\mathbf{m S v})$ & Type of dose \\
\hline Sheltering & $5-15$ & Total Effective dose $(24 \mathrm{~h})$ \\
$\begin{array}{l}\text { Stable iodine prophy- } \\
\text { laxis }\end{array}$ & $10-50$ & $\begin{array}{l}\text { Thyroid equivalent dose (Children }<18 \mathrm{y} \\
\text { and pregnant and breastfeeding women) }\end{array}$ \\
& $50-100$ & $\begin{array}{l}\text { Thyroid equivalent dose (adult) } \\
\text { Evacuation }\end{array}$ \\
\hline
\end{tabular}

Table II

"Derived" intervention levels for the food chain protection in nuclear/radiological emergency situations $\left(\mathrm{Bq} / \mathrm{m}^{2}\right)$.

\begin{tabular}{lll}
\hline & Iodine & Cesium \\
\cline { 2 - 3 } & $4000($ milk) & 6000 (eggs) \\
Activity deposition $\left(\mathrm{Bq} / \mathrm{m}^{2}\right)$ & $10000(\mathrm{eggs})$ & $10000(\mathrm{milk})$ \\
& 40000 (meat) & 10000 (meat) \\
\hline
\end{tabular}

In this paper, the new ICRP approach for the management of a nuclear/radiological emergency situation is compared to the response given by the actual Belgian nuclear emergency plan for three different scenarios. The aim of the study is to compare for each scenario the response from these two approaches on the basis of the intervention levels and the related protective actions. This comparison study is based on the atmospheric dispersion and dose calculations performed with the JRODOS decision support system (Raskob et al., 2011) and the Noodplan models (Camps, 2010). The authors want to limit the analysis of this study to a comparison based on the references/interventions levels criteria only without introducing the optimization process what normally takes place in both approaches.

\section{Scenarios and discussion}

All scenarios used for this comparison study are fictitious nuclear or radiological accident scenarios from one of the nuclear installations located in Belgium. Despite the fact that they have been simplified to illustrate the differences between the two approaches in terms of nuclear emergency management, they remain absolutely realistic.

The first scenario is a constant release through the emergency ventilation system of a mixture of xenon, iodine and caesium during 6 hours from reactor $n^{\circ} 2$ of the Tihange nuclear power plant located in South Belgium. The total activities released are 4.5 PBq for ${ }^{133} \mathrm{Xe}, 300 \mathrm{TBq}$ for ${ }^{131} \mathrm{I}$ and $300 \mathrm{TBq}$ for ${ }^{137} \mathrm{Cs}$. Typical constant meteorological conditions with medium rain intensity have been selected for the atmospheric dispersion and dose calculations and the ingestion exposure pathway has not been considered. Under these conditions, the predicted deposition of 
iodine and caesium calculated with JRODOS are important; for instance, the predicted caesium deposition exceeds $1 \mathrm{MBq} / \mathrm{m}^{2}$ within the first $15 \mathrm{~km}$ distance from the release point. In this case the wet deposition will have a strong impact on the dose assessment especially for the long-lived ${ }^{137} \mathrm{Cs}$. From the Belgian emergency plan viewpoint, only the threshold for the thyroid equivalent dose for children is exceeded in this case and requires stable iodine prophylaxis for children under 18 years old and pregnant and breastfeeding women. However, if we consider a longer integration time for the dose calculation, the maximum groundshine dose given by JRODOS exceeds the upper limit of the new ICRP reference level (see Tab. III). Accordingly, the ICRP approach would require in this case an additional

Table III

Dose calculation results $(\mathrm{mSv})$ using JRODOS for scenario 1 during the first year, at the maximum impact location.

\begin{tabular}{lcccc} 
& $\mathbf{2 4 h}$ & $\mathbf{7}$ days & $\mathbf{1}$ month & $\mathbf{1}$ year \\
\cline { 2 - 5 } Effective cloudshine dose & $1.73 \mathrm{E}-2$ & $1.73 \mathrm{E}-2$ & $1.73 \mathrm{E}-2$ & $1.73 \mathrm{E}-2$ \\
Effective inhalation dose & 0.56 & 0.56 & 0.56 & 0.56 \\
\hline Effective groundshine dose & 0.79 & 4.97 & 16.87 & $\mathbf{1 2 6 . 2}$ \\
Total effective dose & 1.37 & 5.55 & 17.45 & $\mathbf{1 2 6 . 8}$ \\
\hline
\end{tabular}

protective action, for instance temporary relocation in the most contaminated area. The optimization process recommends by the ICRP 109 (ICRP, 2007) guidance would probably lead to an enlargement of the region considered by the relocation countermeasure. The second scenario considered is based on a fast discharge into the atmosphere of a mixture of nobles gases $(\mathrm{NG})$ and iodine radioisotopes $\left(\Sigma \mathrm{NG} \sim 400 \mathrm{TBq}\right.$ and $\Sigma$ iodine $\sim 13 \mathrm{TBq}$ ) from a medical isotope ${ }^{99}$ Mo production facility. The accident occurs at the beginning of the production process during the dissolution of freshly irradiated uranium targets (Salacz, 1985). The activities released account for $100 \%$ and $20 \%$ of the typical inventory for noble gases and iodines, respectively. The maximum effective dose for adults calculated by JRODOS for this scenario after 1 year is equal to $0.4 \mathrm{mSv}$ and the thyroid dose for a 1 year child is about $11.3 \mathrm{mSv}$. These two values are far below the minimum reference level of the new ICRP guidance. In the absence of the optimization process and according to the new ICRP criteria, no protective actions should be taken. Nevertheless, in this case the Belgian authorities will probably advise stable iodine prophylaxis because the thyroid dose for children $(11.3 \mathrm{mSv}$ for a 1 year child) exceeds the current Belgian intervention level $(10 \mathrm{mSv})$. The last scenario shows the importance of the ingestion pathway during a nuclear or radiological emergency situation. In this scenario, the ${ }^{137} \mathrm{Cs}$ deposition is calculated with the atmospheric dispersion model Noodplan for a release of $450 \mathrm{TBq}$ from the NPP Doel (see Fig. 1). The dose assessment shows that references levels of the new ICRP recommendations and the Belgian intervention levels are not exceeded if food chain contribution is not considered. However, if we consider the ingestion pathway, the total effective dose predicted by JRODOS for the region contaminated with more than $50 \mathrm{kBq} / \mathrm{m}^{2}$ of ${ }^{137} \mathrm{Cs}$ is higher than $32 \mathrm{mSv}$ after 1 year if no countermeasures for the food chain are implemented. If we assume that no food 


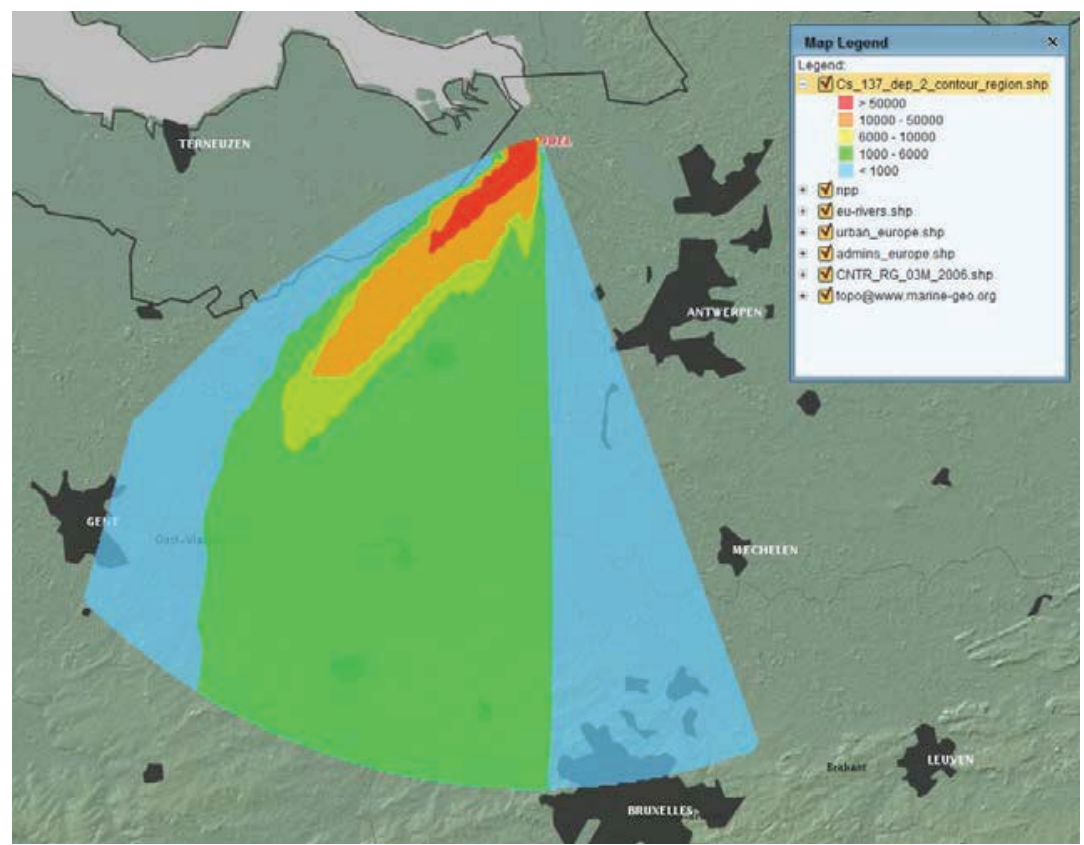

Figure 1 - Aerosol deposition calculated for the scenario 3 with "Noodplan Doel” (visualized using JRODOS), deposition values in $\mathrm{Bq} / \mathrm{m}^{2}$.

products exceeding the European Union intervention levels are consumed, the ingestion dose would be equal to $4.3 \mathrm{mSv}$ for a Belgian diet. For this scenario the main difference between the Belgian emergency plan and the new ICRP recommendations are reflected in the area where food restrictions would be applied; the countermeasures for the food chain would cover a larger surface if we consider the actual Belgian guidance. For the purpose of illustration, the yellow zone in Figure 1 is the region where countermeasures for the food chain should be applied if the derived Belgian intervention levels are considered, while the red zone corresponds to the new ICRP criteria.

Nevertheless protective actions are always considered in a real case where the optimisation process is taken into account for reaching the optimal residual dose considering all exposure pathways.

\section{Conclusions}

The new ICRP approach and the Belgian nuclear emergency plan guidelines lead to similar results in most cases. However, some differences have been observed. These are mainly due to the fact that the Belgian Nuclear emergency plan focuses on the early phase (first week) of a radiological or nuclear accident, while the new ICRP recommendations consider also effects on a longer term. Important 
differences were highlighted by accident scenarios where long-lived isotopes are released, as in the first scenario of this study. A clear difference for setting reference levels for the thyroid dose - especially for children - is observed between the ICRP recommendation and the Belgian approach. The combination of two intervention levels (general reference level and an individual level for particular countermeasures) could thus be very effective for the protection of the population during emergency exposures. In addition, the contribution of ingestion to the total dose should always be taken into account, as it can have a high contribution to the total dose compared to the other exposure pathways, especially in the longer term.

\section{REFERENCES}

Camps J. et al. (2010) The "NOODPLAN" early phase nuclear emergency models: an evaluation. In: Proceedings of the Third European IRPA Congress, 1418 June 2010, Helsinki, Finland.

Euratom (1987) Concil Regulation n²218/89, Official Journal of the European Communities, July 1987, pp. 211-213.

Govaerts P. (1992) Afgeleide referentieniveaus ter ondersteuning van beslissingen in de landbouwsector in geval van een nukleair ongeval, Nukleair risiko en landbouw, IIIde sectie, pp. 120-131. Ministerie van volkgezondheid en leefmilieu.

ICRP Publication 109 (2009) Application of the Commission's Recommendations for the Protection of People in Emergency Exposure Situations, Ann. ICRP 39 (1).

NEA (2003) Short-term Countermeasures in Case of a Nuclear or Radiological Emergency, 1-111, ISBN: 92-64-02140-X.

Raskob W., Trybushnyi D., Ievdin I., Zheleznyak M. (2011) JRODOS: Platform for improved long term countermeasures modelling and management, Radioprotection 46 (6), S731-S736.

Royal Decree (17-10-2003), Arrêté royal portant fixation du plan d'urgence nucléaire et radiologique pour le territoire belge.

Salacz J. (1985) Reprocessing of irradiated Uranium-235 for the production of Mo-99, I-131, Xe-133 radioisotopes, Revue IRE 9, 22-28. 